\title{
Value of influenza vaccines in cancer patients during the coronavirus (COVID-19) pandemic: a cross-sectional study
}

\author{
Mozaffar Aznab $^{1}$ (D) Narges Eskandari Roozbahani ${ }^{2}$ (D) Homa Moazen $^{3}$ (D) \\ Received: 22 December 2020 / Accepted: 5 April 2021 / Published online: 10 April 2021 \\ (C) The Author(s), under exclusive licence to Springer-Verlag GmbH Germany, part of Springer Nature 2021
}

\begin{abstract}
Background According to the recommendation of the Centers for Disease Control and Prevention (CDC), getting influenza vaccines during the coronavirus (COVID-19) pandemics is especially important for people with certain underlying medical conditions, like cancer. Due to the similarities between the symptoms of influenza and COVID-19, receiving the flu vaccine in suspicious cases can be helpful because it will make it easier to request a medical test and diagnosis. In this study, the value of influenza vaccination in the cancer population was investigated.

Methods In a cross-sectional study, all cancer patients who were referred to our clinic and had eligibility to receive the flu vaccine were included in our study for following up clinical signs every week for one month. All patients who were vaccinated from October 1 to November 15, 2020 were investigated. The most side effects that were followed were fever, runny nose, bone pain, and life-threatening or persistent adverse effects.

Results From a total of 288 patients (median age: 52 years (range 18-79), 112 (38.9\%) males and 176 (61.1\%) female) with different types of cancers, only two patients had an adverse effect of vaccination (including bone pain, runny nose, and fatigue), and one had COVID-19 ten days after vaccination. The rest of the patients did not show any side effects due to flu vaccination after one month of follow-up. Cancer patients are recommended to receive the flu vaccine annually during the pandemic and after the end of this pandemic, usually during the flu epidemic season to reduce mortality.
\end{abstract}

Keywords Influenza vaccines $\cdot$ Cancer patient $\cdot$ COVID-19 $\cdot$ Pandemics

\section{Introduction}

Getting a flu vaccine during the coronavirus (COVID-19) pandemic is especially important for people with certain underlying medical conditions, like cancer. Cancer or its

Narges Eskandari Roozbahani

neskandari32@gmail.com

Mozaffar Aznab

draznab@yahoo.com

Homa Moazen

h.moazen64@yahoo.com

1 Professor of Medical Oncology-Hematology, Internal Medicine Department, Kermanshah University of Medical Science, Kermanshah, Iran

2 Clinical Research Development Center, Imam Reza Hospital, Kermanshah University of Medical Sciences, Kermanshah, Iran

3 Department of Biostatics and Epidemiology, Shahid Sadoughi University of Medical Science, Yazd, Iran treatment can lower the resistance to infection and is more likely to catch the flu. The flu vaccination makes it less likely that cancer patients catch the flu. In cancer patients, active immunization has been shown to confer protective immunity against several infections at similar rates to healthy individuals, which has translated into decreased duration and severity of the infection and potentially improved morbidity and mortality [1]. The Centers for Disease Control and Prevention (CDC) recommends annual flu vaccinations for high-risk populations, including health care workers, the elderly, and patients with immunodeficiency or chronic and malignant diseases. Influenza vaccines released this year (2019-2020) are quadrivalent, protecting against four different types of flu. For influenza $A$, the vaccine contains $\mathrm{H} 3 \mathrm{~N} 2$ and H1N1. For influenza B, it covers the Victoria lineage (a new type of influenza B) and the Yamagata lineage [2].

Before the coronavirus pandemic, less than $50 \%$ of patients receiving chemotherapy typically received influenza vaccination $[3,4]$. On the other hand, due to the similarities between the symptoms of influenza and COVID-19, receiving the flu 
vaccine in suspicious cases can be helpful because it will make it easier to request a medical test and diagnosis.

The prevalence of this pandemic raises the question of whether it is safe to receive the flu vaccine even during a coronavirus pandemic in high-risk individuals such as cancer patients. This study was performed to evaluate the value of influenza vaccination in the cancer population.

\section{Subject and methods}

Procedures adopted in this study have been approved by the local ethics committee and are according to the Declaration of Helsinki principles.

This cross-sectional descriptive study has been organized according to the STROBE checklist. All cancer patients who were referred to our clinic and had eligibility to receive the flu vaccine (InfluVac TETRA 2020/2021 surface antigen/inactivate, Abbott Biological B.V, Netherlands) were included in our study for the following up clinical signs every week for one month. The types of cancers in our study and the treatments used for each are presented in Table 1. Those patients who were vaccinated (one $0.5 \mathrm{ml}$ dose) from October 1 to November 15, 2020 were investigated. In terms of cancer type, patients were divided into two categories: hematologic cancer (including multiple myeloma, lymphoma, and Hodgkin's disease) and solid cancer (other than hematological) (Table 2).

However, most patients with hematologic malignancy were not candidates for the vaccine due to the type of treatment they received, such as rituximab. Since this study was performed in a single clinical center and on a limited number of patients with various types of cancers, it can be said that maybe there is a selection bias in this study.

The time for vaccination in those who had received chemotherapy every 3 weeks was the end of the third week and before the start of a new course of chemotherapy, although the new term was postponed for 4 days. The same is true for 2-week treatments. Patients were evaluated for white blood cell (WBC) counts before receiving the vaccine, and only those with $>3000 / \mathrm{mm}^{3}$ WBC were vaccinated.

Side effects listed in the vaccine leaflet, such as headache, fatigue, sweating, myalgia, arthralgia, malaise, local reactions, and shivering [5], were common complications that could occur in cancer patients due to either disease or chemotherapy. For this reason, the most side effects that were followed were fever, bone pain, and life-threatening or persistent adverse effects.

Data were analyzed using the SPSS 22 statistical software and reported as frequency (percentage) and mean ( \pm standard deviation).

\section{Results}

A total of 289 patients (median age: 52 years (range 18-79), $112(38.9 \%)$ males and $176(61.1 \%)$ female) were included. They were under chemotherapy for biliary tract $(2.4 \%)$, bladder $(1 \%)$, breast $(37.2 \%)$, cervix $(0.7 \%)$, gastrointestinal $(29.5 \%)$, lung $(4.9 \%)$, melanoma $(0.7 \%)$, ovarian $(2.1 \%)$, pancreas $(2.1 \%)$, salivary and parotid $(0.7 \%)$, testis and prostate (1.4\%), and hematological cancers (10.1\%) (Tables 1 and 2). Out of 289 patients under study, one patient did not receive the vaccine due to egg allergy. Five patients under rituximab therapy did not experience any side effects after receiving the flu vaccine (Table 3 ). Indeed, these patients without coordination with the oncologist had received the flu vaccine from the regional health center. Patients with comorbidities other than cancer (including liver transplant, congestive heart failure, rheumatoid arthritis, and renal failure) also reported no side effects within a month after receiving the flu vaccine.

Three patients with colon cancer and one patient with multiple myeloma had a history of COVID-19 before receiving the vaccine. These patients were well after receiving the flu vaccine. One of the patients with biliary tract cancer, after receiving the flu vaccine, became infected with coronavirus through medical staff; however, he returned to the normal feeling after a few days. This patient had a dry cough, shortness of breath, and saturation $\mathrm{O}_{2} 90 \%$, and according to the CT scan report, the pulmonary involvement was not severe. Reverse transcription-polymerase chain reaction (RT-PCR), besides the computerized tomography (CT) scan, was the main technique in diagnosing COVID-19. One case of patients with colon cancer (stage IV) and a history of CVID-19 suffered from the vaccine's side effects such as bone pain, fatigue, diarrhea, and runny nose. Besides, a patient with metastatic breast cancer (stage IV) had significant side effects 4 days after receiving the vaccine, which resolved after 15 days. This patient had a fever, shivering, myalgia, headache, severe fatigue, and sweating (Table 4).

\section{Discussion}

Influenza is one of the most common infectious diseases that in seasonal flu epidemics affect different people in all age groups. Infections caused by the virus can be very serious, and lead to severe post-influenza complications, including primary influenza pneumonia or secondary bacterial pneumonia. Complications of influenza are more common, especially in the elderly and in patients with malignancies due to deficiencies in humoral and cellular immunity.

Factors involved in the development of an effective immune response to the vaccine include baseline immunoglobulin IgG levels, immune status, the presence of active disease, the previous or current treatment, age, and the previous 
Table 1 The chemotherapy program for cancer patients eligible to receive the flu vaccine during the COVID-19 pandemic

\begin{tabular}{|c|c|}
\hline Cancer types & Chemotherapy \\
\hline Amyloidosis & Melph/PRD \\
\hline Biliary tract & Gem/Cis/5FU or Capaci/Erlo \\
\hline Bladder & $\mathrm{Gem} / \mathrm{Cis}$ \\
\hline Brain & PVC \\
\hline Breast & TEC or Gem/Nav or Herceptin or Capaci/Nav or Everolimus \\
\hline Cervix & $\mathrm{Tax} / \mathrm{Carb} / \mathrm{Av}$ or Tax/Doxo/Cis \\
\hline CLL & Chlo/PRD \\
\hline Colon & Folfox/Av or Capaci/OX or Folfiri/Av or Folfiri/Erb or Regorafenib \\
\hline Desmoid tumor & Doxo \\
\hline $\mathrm{SCC}$ & $\mathrm{Tax} / \mathrm{Cis} / 5 \mathrm{FU}$ \\
\hline Esophagus & $\mathrm{Tax} / \mathrm{Cis} / 5 \mathrm{FU}$ \\
\hline Gastric & Folfiri/Carb or Tax/Cis/5FU \\
\hline GBM & PVC \\
\hline $\mathrm{HCC}$ & Nexavar \\
\hline HD & $\mathrm{ABVD}$ or Benda/Gem \\
\hline Lung & Tax/Carb or Etop/Cis \\
\hline Lymphoma & Rituximab \\
\hline Melanoma & DTIC/INF-gamma \\
\hline MM & CVAD-Th or Melph/PRD or lenalidomide \\
\hline NPC & Tax/Cis/5FU/ER \\
\hline Osteosarcoma & Tax/Gem \\
\hline Ovarian & Tax/Carb or Tax/Carb/Av or Caelyx/Car \\
\hline Pancreas & $\mathrm{Gem} / \mathrm{Cis} / 5 \mathrm{FU}$ \\
\hline Parotid & Tax/Cis/5FU \\
\hline Periampullary & $\mathrm{Gem} / \mathrm{Cis} / \mathrm{F}$ \\
\hline Prostate & Docetaxel (Taxotere) \\
\hline Rectum & Folfox/Av \\
\hline Salivary gland & $\mathrm{Tax} / \mathrm{Cis} / 5 \mathrm{FU}$ \\
\hline Small intestine & Folfiri/Av \\
\hline Uterine & Tax/Doxo/Cis \\
\hline
\end{tabular}

Melph melphalan; PRD prednison; Gem gemcitabine; Cis cisplatin; Capaci capecitabine; Nav Navelbine; TEC taxotere-epirubicin-cyclophosphamide; $P V C$ procarbazine-lomustine-vincristine; Carb carboplatin; Av Avastin (bevacizumab); Tax paclitaxel; Doxo doxorubicin; Chlo chlorambucil; Folfox folinic acid (leucovorin)-fluorouracil (5FU)-oxaliplatin (Eloxatin); $5 F U$ 5-fluorouracil; Folfiri leucovorin calcium (folinic acid)-fluorouracilirinotecan hydrochloride; $E r b$ erbitux (cetuximab); $A B V D$ adriamycin (doxorubicin)-bleomycine-vinblastinedacarbazine; Benda bendamustin; Etop etoposide; DTIC dacarbazine; INF interferon; CVAD-Th cyclophosphamide, vincristine, doxorubicin, dexamethasone-thalidomide; $H D$ Hodgkin's disease; $M M$ multiple myeloma; $H C C$ hepatic cell carcinoma; SCC squamous cell carcinoma; $C L L$ chronic lymphocytic leukemia; $G B M$ glioblastoma multiform vaccines [6]. In this study, which evaluated the value of the flu vaccination in patients with various malignancies during the COVID-19 pandemic, patients were divided into two categories: solid cancer and hematological cancer.

There is always this pessimism in the medical community about receiving the flu vaccine in patients with hematologic cancer due to changes in the immune system induced by the disease or following chemotherapy. This issue has become more pronounced in the coronavirus pandemic due to the potential for vaccine ineffectiveness and its potentially harmful side effects. However, it should not be overlooked that infections are the leading cause of death in patients with hematologic cancers [7]. Patients with hematologic cancer in this study included multiple myeloma, lymphoma, and Hodgkin's disease. There have been recommendations in previous reports about the requisiteness to administer the flu vaccine to this group of patients. Rapezzi et al. examined the effects of the influenza vaccine in 34 patients with hematological cancer during the flu season (October to April). The results of their studies showed 
Table 2 Frequency, percentage, and mean \pm standard deviation age of eligible cancer patients for getting influenza vaccine (vaccination from October 1 to November 15, 2020)

\begin{tabular}{lllllll}
\hline Type & Frequency & Percent & Mean & SD & Min & Max \\
\hline Biliary tract & 7 & 2.4 & 54.43 & 7.5 & 43 & 63 \\
Bladder & 3 & 1.0 & 61 & 2.000 & 59 & 63 \\
Breast & 107 & 37.2 & 48.34 & 11.6 & 27 & 74 \\
Cervix & 2 & 0.7 & 46 & 8.5 & 40 & 52 \\
Gastrointestinal & 85 & 29.5 & 56.28 & 11.5 & 26 & 76 \\
Glioblastoma multiform & 4 & 1.4 & 51.25 & 2.9 & 49 & 55 \\
Hematological & 29 & 10.1 & 51.66 & 16.5 & 18 & 78 \\
Lung & 14 & 4.9 & 58 & 7.5 & 43 & 66 \\
Melanoma & 2 & 0.7 & 41 & 4.2 & 38 & 44 \\
Metastasis of unknown origin & 2 & 0.7 & 55.5 & 6.4 & 51 & 60 \\
Nasopharyngeal carcinoma & 2 & 0.7 & 34 & 2.8 & 32 & 36 \\
Osteosarcoma & 2 & 0.7 & 33 & 1.4 & 32 & 34 \\
Ovarian & 6 & 2.1 & 49 & 12.3 & 35 & 64 \\
Pancreas & 6 & 2.1 & 55.33 & 8.4 & 48 & 66 \\
Salivary and parotid & 2 & 0.7 & 59 & 24 & 42 & 76 \\
Sarcoma & 2 & 0.7 & 42 & 0.0 & 42 & 42 \\
Testis and prostate & 4 & 1.4 & 58 & 21.1 & 29 & 79 \\
Uterine & 3 & 1.0 & 54.33 & 7.0 & 47 & 61 \\
Other* & 6 & 2.1 & 46 & 11.5 & 31 & 66 \\
Total & 288 & 100.0 & 51.92 & 12.46 & 18 & 79 \\
\hline
\end{tabular}

*Other cancers include brain, desmoids, hepatocellular carcinoma, periampullary, squamous cell carcinoma, and thymoma
Table 3 Frequency and percentage of eligible cancer patients for getting influenza vaccine in terms of COVID-19 disease or history of that, comorbidity, and the adverse effect of vaccination based on demographic variables and disease stage in different types of cancer (vaccination from October 1 to November 15, 2020)

\begin{tabular}{|c|c|c|c|c|c|c|c|c|}
\hline \multirow[t]{2}{*}{ Variable } & \multirow[t]{2}{*}{ Categorical } & \multicolumn{2}{|c|}{ COVID-19 } & \multicolumn{2}{|c|}{ Comorbidity } & \multicolumn{2}{|c|}{ The adverse effect of vaccination } & \multirow[t]{2}{*}{ Total } \\
\hline & & Yes & No & Yes & No & Yes & No & \\
\hline \multirow[t]{4}{*}{ Gender } & \multirow[t]{2}{*}{ Male } & 3 & 109 & 2 & 110 & 1 & 111 & \multirow[t]{2}{*}{112} \\
\hline & & $2.7 \%$ & $97.3 \%$ & $1.8 \%$ & $98.2 \%$ & $0.9 \%$ & $99.1 \%$ & \\
\hline & \multirow{2}{*}{ Female } & 2 & 174 & 2 & 174 & 1 & 175 & \multirow[t]{2}{*}{176} \\
\hline & & $1.1 \%$ & $98.9 \%$ & $1.1 \%$ & $98.9 \%$ & $0.6 \%$ & $99.4 \%$ & \\
\hline \multirow[t]{6}{*}{ Age group } & \multirow[t]{2}{*}{$<40$} & 1 & 48 & 1 & 48 & 0 & 49 & \multirow[t]{2}{*}{49} \\
\hline & & $2.0 \%$ & $98.0 \%$ & $2.0 \%$ & $98.0 \%$ & $0.0 \%$ & $100.0 \%$ & \\
\hline & \multirow[t]{2}{*}{$40-59$} & 3 & 150 & 2 & 151 & 2 & 151 & \multirow[t]{2}{*}{153} \\
\hline & & $2.0 \%$ & $98.0 \%$ & $1.3 \%$ & $98.7 \%$ & $1.3 \%$ & $98.7 \%$ & \\
\hline & \multirow[t]{2}{*}{$\geq 60$} & 1 & 85 & 1 & 85 & 0 & 86 & \multirow[t]{2}{*}{86} \\
\hline & & $1.2 \%$ & $98.8 \%$ & $1.2 \%$ & $98.8 \%$ & $0.0 \%$ & $100.0 \%$ & \\
\hline \multirow[t]{10}{*}{ Stage } & \multirow[t]{2}{*}{ II } & 0 & 51 & 0 & 51 & 0 & 51 & \multirow[t]{2}{*}{51} \\
\hline & & $0.0 \%$ & $100.0 \%$ & $0.0 \%$ & $100.0 \%$ & $0.0 \%$ & $100.0 \%$ & \\
\hline & \multirow[t]{2}{*}{ III } & 1 & 77 & 2 & 76 & 0 & 78 & \multirow[t]{2}{*}{78} \\
\hline & & $1.3 \%$ & $98.7 \%$ & $2.6 \%$ & $97.4 \%$ & $0.0 \%$ & $100.0 \%$ & \\
\hline & \multirow[t]{2}{*}{ IV } & 2 & 86 & 1 & 87 & 2 & 86 & \multirow[t]{2}{*}{88} \\
\hline & & $2.3 \%$ & $97.7 \%$ & $1.1 \%$ & $98.9 \%$ & $2.3 \%$ & $97.7 \%$ & \\
\hline & \multirow[t]{2}{*}{ Relapsed } & 0 & 33 & 0 & 33 & 0 & 33 & \multirow[t]{2}{*}{33} \\
\hline & & $0.0 \%$ & $100.0 \%$ & $0.0 \%$ & $100.0 \%$ & $0.0 \%$ & $100.0 \%$ & \\
\hline & \multirow[t]{2}{*}{ Unknown } & 2 & 36 & 1 & 37 & 0 & 38 & \multirow[t]{2}{*}{38} \\
\hline & & $5.3 \%$ & $94.7 \%$ & $2.6 \%$ & $97.4 \%$ & $0.0 \%$ & $100.0 \%$ & \\
\hline \multirow[t]{4}{*}{ Rituximab } & \multirow[t]{2}{*}{ Yes } & 0 & 5 & 0 & 5 & 0 & 5 & 5 \\
\hline & & $0.0 \%$ & $100.0 \%$ & $0.0 \%$ & $100.0 \%$ & $0.0 \%$ & $100.0 \%$ & \\
\hline & No & 5 & 278 & 4 & 279 & 2 & 281 & 283 \\
\hline & & $1.8 \%$ & $98.2 \%$ & $1.4 \%$ & $98.6 \%$ & $0.7 \%$ & $99.3 \%$ & \\
\hline Total & & $5^{*}$ & 283 & $4 * *$ & 284 & $2 * * *$ & 287 & 288 \\
\hline
\end{tabular}

*Four patients before the vaccination and one (a 48-year-old woman with biliary tract cancer) after the vaccination got COVID-19

**Patients with comorbidities other than cancer (including liver transplant, congestive heart failure, rheumatoid arthritis, and renal failure)

***Two patients with colon and breast cancer (grade IV), one of them with a history of COVID-19 before vaccination, 4 and 10 days after vaccination had experienced side effects of vaccination (bone pain, fatigue, and runny nose), respectively 
Table 4 Frequency and percentage of eligible cancer patients for getting influenza vaccine in terms of COVID-19 disease or history of that, comorbidity, and the adverse effect of vaccination based on cancer types (vaccination from October 1 to November 15, 2020)

\begin{tabular}{|c|c|c|c|c|c|c|c|}
\hline \multirow[t]{2}{*}{ Type } & \multicolumn{2}{|c|}{ COVID-19 } & \multicolumn{2}{|c|}{ Comorbidity } & \multicolumn{2}{|c|}{ The adverse effect of vaccination } & \multirow[t]{2}{*}{ Total } \\
\hline & Yes & No & Yes & No & Yes & No & \\
\hline Biliary tract & $\begin{array}{l}1 \\
14.3 \%\end{array}$ & $\begin{array}{l}6 \\
85.7 \%\end{array}$ & $\begin{array}{l}0 \\
0.0 \%\end{array}$ & $\begin{array}{l}7 \\
100.0 \%\end{array}$ & $\begin{array}{l}0 \\
0.0 \%\end{array}$ & $\begin{array}{l}7 \\
100.0 \%\end{array}$ & 7 \\
\hline Bladder & $\begin{array}{l}0 \\
0.0 \%\end{array}$ & $\begin{array}{l}3 \\
100.0 \%\end{array}$ & $\begin{array}{l}0 \\
0.0 \%\end{array}$ & $\begin{array}{l}3 \\
100.0 \%\end{array}$ & $\begin{array}{l}0 \\
0.0 \%\end{array}$ & $\begin{array}{l}3 \\
100.0 \%\end{array}$ & 3 \\
\hline Breast & $\begin{array}{l}0 \\
0.0 \%\end{array}$ & $\begin{array}{l}107 \\
100.0 \%\end{array}$ & $\begin{array}{l}1 \\
0.9 \%\end{array}$ & $\begin{array}{l}106 \\
99.1 \%\end{array}$ & $\begin{array}{l}1 \\
0.9 \%\end{array}$ & $\begin{array}{l}106 \\
99.1 \%\end{array}$ & 107 \\
\hline Cervix & $\begin{array}{l}0 \\
0.0 \%\end{array}$ & $\begin{array}{l}2 \\
100.0 \%\end{array}$ & $\begin{array}{l}1 \\
50.0 \%\end{array}$ & $\begin{array}{l}1 \\
50.0 \%\end{array}$ & $\begin{array}{l}0 \\
0.0 \%\end{array}$ & $\begin{array}{l}2 \\
100.0 \%\end{array}$ & 2 \\
\hline Gastrointestinal & $\begin{array}{l}3 \\
3.5 \%\end{array}$ & $\begin{array}{l}82 \\
96.5 \%\end{array}$ & $\begin{array}{l}1 \\
1.2 \%\end{array}$ & $\begin{array}{l}84 \\
98.8 \%\end{array}$ & $\begin{array}{l}1 \\
1.2 \%\end{array}$ & $\begin{array}{l}84 \\
98.8 \%\end{array}$ & 85 \\
\hline Glioblastoma multiform & $\begin{array}{l}0 \\
0.0 \%\end{array}$ & $\begin{array}{l}4 \\
100.0 \%\end{array}$ & $\begin{array}{l}0 \\
0.0 \%\end{array}$ & $\begin{array}{l}4 \\
100.0 \%\end{array}$ & $\begin{array}{l}0 \\
0.0 \%\end{array}$ & $\begin{array}{l}4 \\
100.0 \%\end{array}$ & 4 \\
\hline Hematological & $\begin{array}{l}1 \\
3.4 \%\end{array}$ & $\begin{array}{l}28 \\
96.6 \%\end{array}$ & $\begin{array}{l}0 \\
0.0 \%\end{array}$ & $\begin{array}{l}29 \\
100.0 \%\end{array}$ & $\begin{array}{l}0 \\
0.0 \%\end{array}$ & $\begin{array}{l}29 \\
100.0 \%\end{array}$ & 29 \\
\hline Lung & $\begin{array}{l}0 \\
0.0 \%\end{array}$ & $\begin{array}{l}14 \\
100.0 \%\end{array}$ & $\begin{array}{l}0 \\
0.0 \%\end{array}$ & $\begin{array}{l}14 \\
100.0 \%\end{array}$ & $\begin{array}{l}0 \\
0.0 \%\end{array}$ & $\begin{array}{l}14 \\
100.0 \%\end{array}$ & 14 \\
\hline Melanoma & $\begin{array}{l}0 \\
0.0 \%\end{array}$ & $\begin{array}{l}2 \\
100.0 \%\end{array}$ & $\begin{array}{l}0 \\
0.0 \%\end{array}$ & $\begin{array}{l}2 \\
100.0 \%\end{array}$ & $\begin{array}{l}0 \\
0.0 \%\end{array}$ & $\begin{array}{l}2 \\
100.0 \%\end{array}$ & 2 \\
\hline Metastasis of unknown origin & $\begin{array}{l}0 \\
0.0 \%\end{array}$ & $\begin{array}{l}2 \\
100.0 \%\end{array}$ & $\begin{array}{l}0 \\
0.0 \%\end{array}$ & $\begin{array}{l}2 \\
100.0 \%\end{array}$ & $\begin{array}{l}0 \\
0.0 \%\end{array}$ & $\begin{array}{l}2 \\
100.0 \%\end{array}$ & 2 \\
\hline Nasopharyngeal carcinoma & $\begin{array}{l}0 \\
0.0 \%\end{array}$ & $\begin{array}{l}2 \\
100.0 \%\end{array}$ & $\begin{array}{l}0 \\
0.0 \%\end{array}$ & $\begin{array}{l}2 \\
100.0 \%\end{array}$ & $\begin{array}{l}0 \\
0.0 \%\end{array}$ & $\begin{array}{l}2 \\
100.0 \%\end{array}$ & 2 \\
\hline Osteosarcoma & $\begin{array}{l}0 \\
0.0 \%\end{array}$ & $\begin{array}{l}2 \\
100.0 \%\end{array}$ & $\begin{array}{l}0 \\
0.0 \%\end{array}$ & $\begin{array}{l}2 \\
100.0 \%\end{array}$ & $\begin{array}{l}0 \\
0.0 \%\end{array}$ & $\begin{array}{l}2 \\
100.0 \%\end{array}$ & 2 \\
\hline Ovarian & $\begin{array}{l}0 \\
0.0 \%\end{array}$ & $\begin{array}{l}6 \\
100.0 \%\end{array}$ & $\begin{array}{l}0 \\
0.0 \%\end{array}$ & $\begin{array}{l}6 \\
100.0 \%\end{array}$ & $\begin{array}{l}0 \\
0.0 \%\end{array}$ & $\begin{array}{l}6 \\
100.0 \%\end{array}$ & 6 \\
\hline Pancreas & $\begin{array}{l}0 \\
0.0 \%\end{array}$ & $\begin{array}{l}6 \\
100.0 \%\end{array}$ & $\begin{array}{l}0 \\
0.0 \%\end{array}$ & $\begin{array}{l}6 \\
100.0 \%\end{array}$ & $\begin{array}{l}0 \\
0.0 \%\end{array}$ & $\begin{array}{l}6 \\
100.0 \%\end{array}$ & 6 \\
\hline Salivary and parotid & $\begin{array}{l}0 \\
0.0 \%\end{array}$ & $\begin{array}{l}2 \\
100.0 \%\end{array}$ & $\begin{array}{l}0 \\
0.0 \%\end{array}$ & $\begin{array}{l}2 \\
100.0 \%\end{array}$ & $\begin{array}{l}0 \\
0.0 \%\end{array}$ & $\begin{array}{l}2 \\
100.0 \%\end{array}$ & 2 \\
\hline Sarcoma & $\begin{array}{l}0 \\
0.0 \%\end{array}$ & $\begin{array}{l}2 \\
100.0 \%\end{array}$ & $\begin{array}{l}0 \\
0.0 \%\end{array}$ & $\begin{array}{l}2 \\
100.0 \%\end{array}$ & $\begin{array}{l}0 \\
0.0 \%\end{array}$ & $\begin{array}{l}2 \\
100.0 \%\end{array}$ & 2 \\
\hline Testis and prostate & $\begin{array}{l}0 \\
0.0 \%\end{array}$ & $\begin{array}{l}4 \\
100.0 \%\end{array}$ & $\begin{array}{l}0 \\
0.0 \%\end{array}$ & $\begin{array}{l}4 \\
100.0 \%\end{array}$ & $\begin{array}{l}0 \\
0.0 \%\end{array}$ & $\begin{array}{l}4 \\
100.0 \%\end{array}$ & 4 \\
\hline Uterine & $\begin{array}{l}0 \\
0.0 \%\end{array}$ & $\begin{array}{l}3 \\
100.0 \%\end{array}$ & $\begin{array}{l}0 \\
0.0 \%\end{array}$ & $\begin{array}{l}3 \\
100.0 \%\end{array}$ & $\begin{array}{l}0 \\
0.0 \%\end{array}$ & $\begin{array}{l}3 \\
100.0 \%\end{array}$ & 3 \\
\hline Other & $\begin{array}{l}0 \\
0.0 \%\end{array}$ & $\begin{array}{l}6 \\
100.0 \%\end{array}$ & $\begin{array}{l}1 \\
16.7 \%\end{array}$ & $\begin{array}{l}5 \\
83.3 \%\end{array}$ & $\begin{array}{l}0 \\
0.0 \%\end{array}$ & $\begin{array}{l}6 \\
100.0 \%\end{array}$ & 6 \\
\hline Total & 5 & 283 & 4 & 284 & 2 & 286 & 288 \\
\hline
\end{tabular}

that there were no adverse reactions after vaccination in these patients and seroprotection and seroconversion were higher than the standard of the European Agency for the Evaluation of Medicinal Products. Only one patient had the flu after a follow-up. They suggested that the flu vaccine could be well tolerated in this group of patients and was not contraindicated [6]. In five vaccinated hematological cancer patients, despite receiving rituximab, no adverse effects of the vaccine were reported. However, previous studies have reported ineffective vaccine immunogenicity in this group of patients. Yri et al. investigated humoral responses to influenza vaccination in lymphoma patients with rituximab monotherapy or combination therapy. They suggested that there is no protective immunity from the vaccine in any case against influenza A (H1N1) 2009 (swine flu virus). They concluded that these patients may not respond well enough 
not only to the flu vaccine but also to other common vaccines [8].

Among those who were vaccinated was a cancer patient with a history of liver transplantation who did not experience the side effects of the vaccine after 1 month of follow-up. The safety and immunogenicity of influenza vaccination in transplant recipients have been previously evaluated $[9,10]$. PérezRomero et al., in a prospective cohort study in 798 solid organ transplant recipients, investigated the safety and immunogenicity of flu vaccination 6 months and more after transplantation. They resulted that influenza vaccination within the first 6 months after transplantation is as safe and immunogenic as vaccination thereafter, so they recommended the administration of flu vaccination as soon as a month after transplantation [11].

Previous findings also suggest that the influenza vaccine in high-risk groups such as the heart [12], kidney [13], and rheumatoid arthritis [14] patients is a cost-effective preventative measure that improves survival and reduces the incidence of underlying disease in high-risk populations.

One of the cancer patients became infected with coronavirus after vaccination, which, of course, was due to the spread of the disease through caregivers. This person, who had previously received the flu vaccine, developed a mild form of the Covid-19 disease without severe pulmonary symptoms. It should be noted, however, that more detailed research is needed to evaluate the effect of the influenza vaccine on susceptibility to Covid-19. According to the recommendations [15] we had to this group of patients in using masks and gloves and maintaining a safe distance to prevent coronavirus disease, the incidence in these patients was very low, and the incidence occurred due to non-compliance with the recommended cases.

\section{Study limitations}

In this study, all patients had a type of cancer and were under chemotherapy. Because this study was performed in a single clinical center, the sample size in each type of cancer cannot be generalized to all cancer patients. Therefore, there may be a selection bias in this study.

On the other hand, our study population did not have the same frequency distribution in cancer subgroups and cancer stages, so the response and non-response to vaccine side effects cannot be attributed to a particular type of cancer or in a particular stage. The frequency of people with breast cancer and gastrointestinal cancer was more than other cancers, so the chances of response in these types of cancer were higher.

Although there were no side effects in people with a history of COVID-19 after flu vaccination, it cannot be concluded that receiving the flu vaccine in cancer patients with a history of COVID-19 had no side effects. To reach this conclusion, more sample size in each type of cancer and from several clinical centers is needed.

\section{Conclusion}

Our study revealed that vaccination in cancer patients during the coronavirus pandemic did not increase the risk of this disease and did not induce severe vaccine-induced complications in patients. Generally, cancer patients are recommended to receive the flu vaccine annually during the pandemic and after the end of this pandemic, usually during the flu epidemic season to reduce mortality.

Author's contribution Aznab M: concepts, design, definition of intellectual content, clinical studies, manuscript preparation, manuscript editing, manuscript review, data acquisition, guarantor; Eskandari Roozbahani N: concepts, design, literature search, data acquisition, data analysis, manuscript preparation, manuscript editing, manuscript review; Moazen $\mathrm{H}$ : literature search, data acquisition, statistical analysis, manuscript preparation, manuscript review.

Availability of data and material No additional data are available.

Code availability N/A.

\section{Declarations}

Ethics approval Procedures adopted in this study have been approved by the local ethics committee and are according to the Declaration of Helsinki principles.

Consent to participate Verbal informed consent was obtained before the interview.

Consent for publication The participant has consented to the submission of the case report in the journal.

Competing interests The authors declare no competing interests.

\section{References}

1. Shehata MA, Karim NA (2014) Influenza vaccination in cancer patients undergoing systemic therapy. Clinical Medicine Insights Oncology 8:57-64

2. M H. Six things you should know about getting your flu shot during the COVID-19 pandemic Minnesota, United States2020. Available from: https://www.mhealth.org/blog/2020/oct-2020/six-things-toknow-about-flu-shots-during-COVID-19-pandemic.

3. Loulergue P, Mir O, Alexandre J, Ropert S, Goldwasser F, Launay O (2008) Low influenza vaccination rate among patients receiving chemotherapy for cancer. Annals of oncology : official journal of the European Society for Medical Oncology 19(9):1658

4. Sommer AL, Wachel BK, Smith JA (2006) Evaluation of vaccine dosing in patients with solid tumors receiving myelosuppressive chemotherapy. Journal of oncology pharmacy practice : official 
publication of the International Society of Oncology Pharmacy Practitioners 12(3):143-154

5. Medical N. Influvac Tetra. 2020.

6. Rapezzi D, Sticchi L, Racchi O, Mangerini R, Ferraris AM, Gaetani GF (2003) Influenza vaccine in chronic lymphoproliferative disorders and multiple myeloma. Eur J Haematol 70(4):225-230

7. Andersen MA, Niemann CU (2018) Immune failure, infection and survival in chronic lymphocytic leukemia in Denmark. Haematologica. 103(7):e330

8. Yri OE, Torfoss D, Hungnes O, Tierens A, Waalen K, Nordøy T, Dudman S, Kilander A, Wader KF, Østenstad B, Ekanger R, Meyer P, Kolstad A (2011) Rituximab blocks protective serologic response to influenza A (H1N1) 2009 vaccination in lymphoma patients during or within 6 months after treatment. Blood. 118(26): 6769-6771

9. Duchini A, Hendry R, Nyberg L, Viernes M, Pockros P (2001) Immune response to influenza vaccine in adult liver transplant recipients. Liver transplantation : official publication of the American Association for the Study of Liver Diseases and the International Liver Transplantation Society 7:311-313

10. Mulley WR, Dendle C, Ling JEH, Knight SR (2018) Does vaccination in solid-organ transplant recipients result in adverse immunologic sequelae? A systematic review and meta-analysis. J Heart Lung Transplant 37(7):844-852

11. Pérez-Romero P, Bulnes-Ramos A, Torre-Cisneros J, Gavaldá J, Aydillo TA, Moreno A, et al. (2015) Influenza vaccination during the first 6 months after solid organ transplantation is efficacious and safe. Clinical Microbiology and Infection 21(11):1040.e11-.e18.

12. Kadoglou NPE, Parissis J, Seferovic P, Filippatos G (2018) Vaccination in heart failure: an approach to improve outcomes. Revista Española de Cardiología (English Edition) 71(9):697-699

13. Miskulin DC, Weiner DE, Tighiouart H, Lacson EK, Meyer KB, Dad T et al (2018) High-dose seasonal influenza vaccine in patients undergoing dialysis. Clin J Am Soc Nephrol 13(11):1703-1711

14. The LR (2020) Fighting flu: the importance of vaccines in rheumatic disease. The Lancet Rheumatology 2(2):e63

15. Aznab M (2020) Evaluation of COVID 19 infection in 279 cancer patients treated during a 90-day period in 2020 pandemic. Int J Clin Oncol 25(9):1581-1586

Publisher's note Springer Nature remains neutral with regard to jurisdictional claims in published maps and institutional affiliations. 